\title{
Insights Arising When Quantum Mechanics is Reappraised From a Biological Perspective
}

\section{Michael Thomas Deans*}

Freelance, 4 Cavendish House, Cavendish Road, Chiswick, London, W4 3TD, UK

*Corresponding author: Deans MT, Freelance, 4 Cavendish House,Cavendish Road, Chiswick, London, W4 3TD, UK, Tel: 020 89956525; E-mail: michaeltdeans@gmail.com

Rec date: Sep 17, 2015; Acc date: Jun 27, 2016; Pub date: Jun 30, 2016

Copyright: () 2016 Deans MT. This is an open-access article distributed under the terms of the Creative Commons Attribution License, which permits unrestricted use, distribution, and reproduction in any medium, provided the original author and source are credited.

\begin{abstract}
A recently reported ferroelectric phase transition at 72 Kelvin in ice XIc corroborates an observation made as a physics student in 1967. I attributed anomalous readings from a silica helium thermometer suspended in liquid nitrogen to distortion by ice crystallizing on its surface, suggesting a proton ordered tetragonal variant, ice It of cubic ice had changed shape during an ordering phase transition releasing latent energy as 'ice light', wavelength $\lambda \sim 4 \mu$ infrared laser light.

My research into its consequences reinterprets the axiomatic basis of science, affording simple accounts of familiar topics. Ice light emitted from pools of nitrogen on Earth's poles during a primordial ice age was multiply reflected in cloud and surface ice, creating DNA, including tRNA analogue 'transport DNAs', tDNAs by selectively polymerizing nucleotides in equatorial waters.
\end{abstract}

They constituted $\mathrm{H}$-bond lined pores through proto-cell membranes, polarization by ice light created an electric field propelling ionic substrate-trace element complexes constituting life's molecular vocabulary inside. 64 tDNA variants orchestrate biochemistry, supplementing trace elements prevents mental and physical maladies.

'Minions' arose from comparing cybernetics, psychology and traditional wisdom. 189 flat anti-parallel $\beta$-sheet hairpins with alternate neutral and basic amino acid residues bind 1,701 DNA base pairs, forming a nine-coil abacus. Minions probably evolved to pack DNA in chromosomes for accurate replication. 189*18 arrays of proton ordered $\mathrm{H}$ bonds connecting amino acid $\omega$-amines to DNA phosphates control metabolism, are biological clocks and 'chips in the brain'.

When sarcomeres of striated muscle contract, they form $1 / 2$-wave resonant cavities for $\lambda$, exemplifying biological energy coupling. Protons accelerated along minion tunnels drive molecular scale nuclear fusion, if coupled they could resolve global warming.

Artificial intelligence modeled on minions would satisfy Turing's vision, allowing for personality and compensating the relativity between perception and conception, reinterpreting quantum mechanics, uncertainty and relativity.

Keywords: Proton ordered hydrogen bond; H-bond; Transport DNA, tDNA; Trace Element Metabolism; Minion DNA-protein complex; Resonant Cavity Couples Energy; Reinterpreting quantum mechanics; Distorted Reality creates new axioms

\section{Introduction}

Solving Professor Brian Pippard's Problems in classical physics as a Cambridge undergraduate convinced me of its validity. When an experiment involving liquid nitrogen produced a hysteresis curve unexpectedly in 1967, I proposed a tetragonal variant of cubic ice, ice Ic (recently confirmed by reports of a phase transition at $72 \mathrm{~K}$ in ice XIc [1], had crystallized on the silica helium thermometer bulb and deformed it.

While employed as a programmer, I noted computer instruction sets could be reduced to nine, suggested the same might apply to human intelligence. A report of chromosomes degrading to strings of nine beads [2] suggested the minion DNA-protein complex.
If the B-helix, Figure 1A is uncoiled, $\mathrm{B}$ and arranged to retain its original spacing, C, like Gramicidin S, D, hydrogen bonds, H-bonds connect its base pairs (C, G, A and T) to the $\omega$-amines of Lys and Arg in an anti-parallel $\beta$-pleated sheet [3] composed of alternate neutral (Ala, Leu, Ile and Val) and basic (Lys and Arg) residues with Pro forming an asymmetric U-bend (mnemonic A LIVe CiGAreTte), E. That $18^{*} 63 \mathrm{H}$-bond array stores an eighteen-letter word using a sixtythree-character alphabet. Those contained in a human cell nucleus could store the Bible, Koran and Shakespeare's works.

Resonant interactions facilitate memory recall, nerve fibers serve as optic cables and synaptic junctions as logic gates. The H-bonds oscillate, constituting biological clocks following Dekatron "logic used in Geiger counters. 
Page 2 of 5

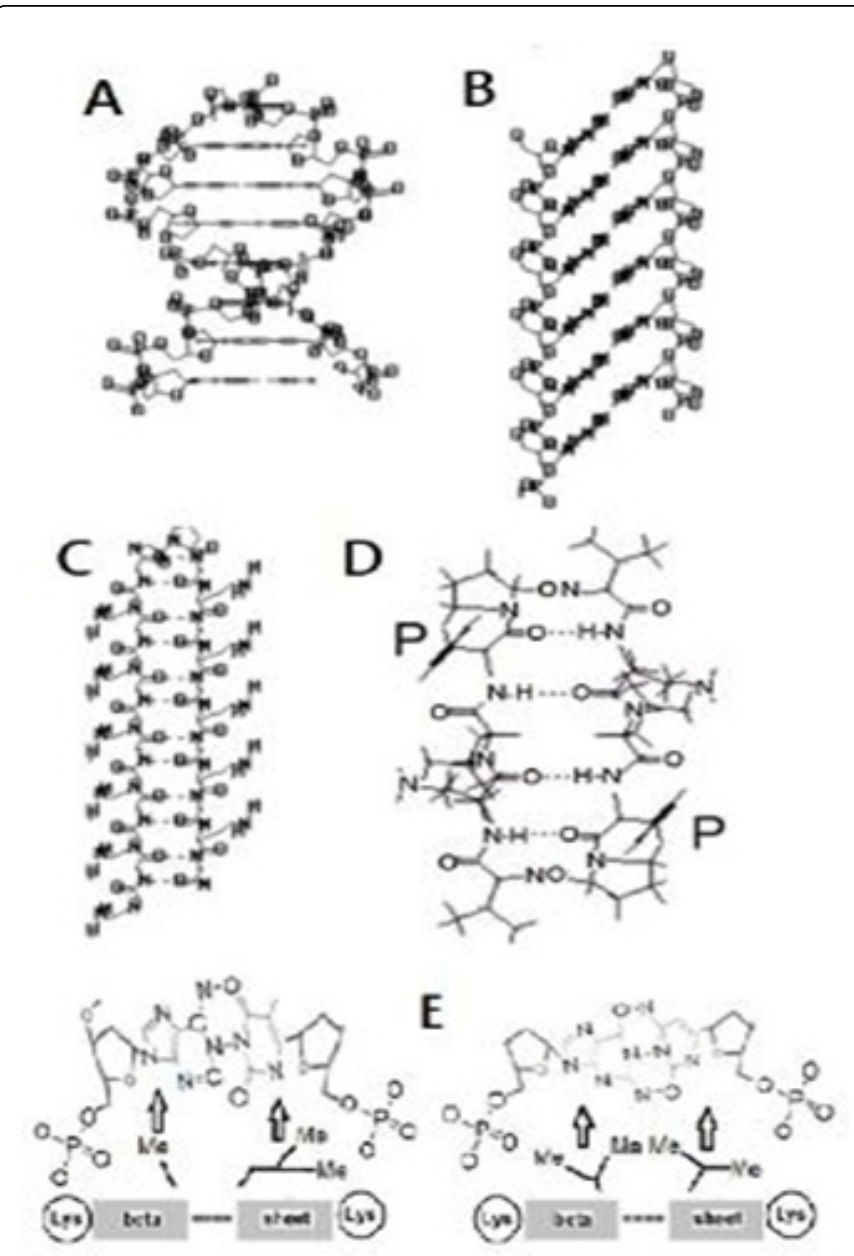

Figure 1: A-C. DNA uncoils to fit protein $\beta$-sheet, analogous to Dphenylalanine in Gramicidin S [4], D. Amino acids match DNA base pairs, E. The Tyger relativity equation, F. describes how minion brain chips distort our perception of light.

$$
\begin{aligned}
& \frac{d^{2} \Theta}{d t^{2}}=\frac{\pi \beta^{2}}{2 \sqrt{e\left([1+\beta]^{t / \tau}+[1+\beta]^{-t / \tau}\right)}} \\
& \frac{d^{2} \Theta}{d t^{2}}=\frac{\pi \beta^{2}}{2 \sqrt{e\left([1+\beta]^{t / \tau}-[1+\beta]^{-t / \tau}\right)}}
\end{aligned}
$$

Their time unit $\tau \approx 1.4^{*} 10-15$ seconds determines the periods of coils 11, 13 and 18, matching day-length, Sun-spot cycle period and the age of the universe respectively. Time is illusory, not equivalent to a linear dimension.

Minions use polar coordinates, $\Theta$ and $\Phi, \beta=63-9=1.39^{*} 10-15$ and $\mathrm{e}=$ base of natural logarithms.

Minions' roles in human intelligence are well supported [5], their instability, degrading to nucleosome core particles [6] on extraction, explains why they've eluded detection. As abaci, they make 1 in $639 \approx$ $1.56{ }^{*} 1016$ wrap-around counting 'errors'.

$\tau$ effectively replace Planck's constant, limiting conception and reinterpreting Heisenberg's uncertainty. Michelson and Morley's determination of the speed of light [7] shattered confidence in the potential of science to explain everything. The Tyger relativity equation, $\mathrm{F}$ translates perception to conception, interpreting planes as spheres, restoring the simplicity of science.

Current scientific axioms were established by Isaac Newton, Michael Faraday added discrete positively charged electric particles, Charles Darwin the concept of evolution and Linus Pauling classified chemical bonds, especially hydrogen bonds.

Karl Popper's philosophy dictates that extrapolations leading to false conclusions justifies their revision but as Piet Hein wrote, Things Take Time. Minion theory confirms Einstein's suspicion of spooky action at a distance [8], affording deeper chemical insights than quantum physics.

I advocate redirecting research resources from cosmology and particle physics to disease prevention, sustainable agriculture and clean energy generation.

\begin{tabular}{|c|c|}
\hline \multicolumn{2}{|l|}{ Using: } \\
\hline $\mathrm{H}$-bond length & $\mathrm{h}=1.75 \AA$ \\
\hline $\mathrm{OH}$-bond length & $\mathrm{b}=1.01 \AA$ \\
\hline Dipole moment & $\mu=1.27^{*} 10-29 \mathrm{~m}$ \\
\hline Dielectric constant & $\varepsilon=3.1$ Faraday $m-1$ \\
\hline Space dielectric const & $\mathrm{E} 0=8.85^{*} 10-12$ Faraday $m-1$ \\
\hline Tetrahedral angle & $\theta a=104.5^{\circ}$ \\
\hline $\mathrm{H}-\mathrm{O}-\mathrm{H}$ bond angle & $\theta b=109.5^{\circ}$ \\
\hline Charge cloud angle & $\theta \mathrm{c}=120^{\circ}$ \\
\hline Velocity of light & $\mathrm{c}=3^{*} 108 \mathrm{~m} / \mathrm{sec}$ \\
\hline Planck's constant & $N=6.63^{*} 1023$ Joule sec \\
\hline
\end{tabular}

\section{Ice, the ordering force:}

\section{Transition temperatures:}

\begin{tabular}{|l|l|}
\hline Hexagonal/cubic & $130 \mathrm{~K}$ \\
\hline Nitrogen boils & $77 \mathrm{~K}$ \\
\hline Cubic/vitreous & $110 \mathrm{~K}$ \\
\hline Ferroelectric & $72 \mathrm{~K}$ \\
\hline
\end{tabular}

\section{Molecular coordinates of water in ice crystals:}

\begin{tabular}{|l|l|}
\hline ice Ic: & $\Delta \mathrm{x}=\Delta \mathrm{y}=2.26 \AA \Delta \mathrm{z}=1.6 \AA$ \\
\hline ice It: & $\Delta \mathrm{x}=\Delta \mathrm{y}=2.32 \AA \Delta \mathrm{z}=1.5 \AA$ \\
\hline
\end{tabular}

The latent energy released by the ferroelectric transition of ice Ic to ice It, Figure $2 \mathrm{~A}$ can be calculated: $22.3 \mathrm{~kJ} /$ mole with wavelength $\approx 4 \mu$, approximating the phosphodiester bond energy of ATP. Some of the 16 known ice forms are orderly, lacking Linus Pauling's residual entropy [9]. 
A

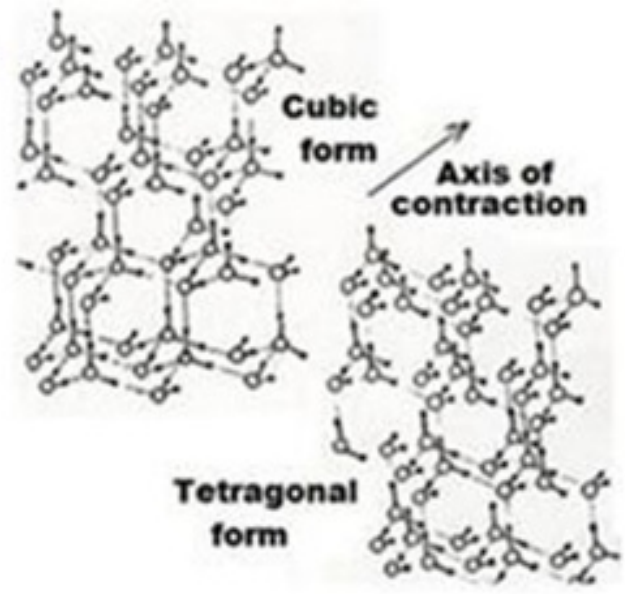

B

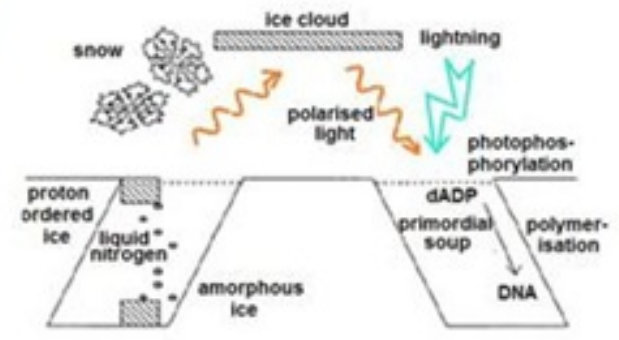

Figure 2: A. Ferroelectric phase transition in ice at 72 Kelvin, B. Origin of life.

\section{Origin of Life}

Joan Baez wrote: My life's like a crystal teardrop in 'Daybreak'. During a primordial ice age, ice crystallizing in pools of liquid nitrogen on Earth's poles morphed from cubic to tetragonal, releasing latent energy as $\sim 4 \mu$ infrared laser light. Reflection by ice in clouds and on Earth's surface shone polarized laser light on Darwin's warm equatorial waters [10], selectively activating nucleotides [11].

Their polymerization created a DNA noodle soup some formed 'transport DNA's, tDNAs, transfer RNA analogues. These fed Oparin's coacervates $[12,13]$ with life's prerequisites. The replication of a tDNA signaled life's beginning.

\section{Active Transport}

Hydrolysis of ATP replaces ice light, releasing $\sim 4 \mu$ laser light driving tDNA pumps. It depolarizes the H-bond-lining their pores, creating a trans-membrane electric field, Figure $3 \mathrm{~A}$.

Before chemical reactions can occur, substrates need concentrating. Originally, nucleotides were slowly concentrated, eventually concatenating to replicate tDNAs in coacervates. Modern tDNAs deploy trace element ions with unique shapes as carriers, selecting a short list of substrates familiar to modern biochemists, C-K.

A: Catecholamines exchange $3 \mathrm{Na}$ for $2 \mathrm{~K}$, B: Sulphite exchanges $\mathrm{Ca}$ for $\mathrm{Mg}$,
C: Manganese chlorides transport $\mathrm{NaCl}, \mathrm{D}$ : Iodinium transports oxygen, E: Copper carries amino acids, F: Silicon hexafluoride transports apatite, G: Zinc is carrier for glucose,

$\mathrm{H}$ : Silver exchanges creatine for creatinine and orchestrates arginine.pyrophosphate transport, I: Selenite exchanges $\mathrm{Ca}$ for $\mathrm{Mn}$ and exchanging phospho-mevalonate for phosspho-mevalono-lactone transports water, contradicting Mitchell's chemiosmosis [14-17].

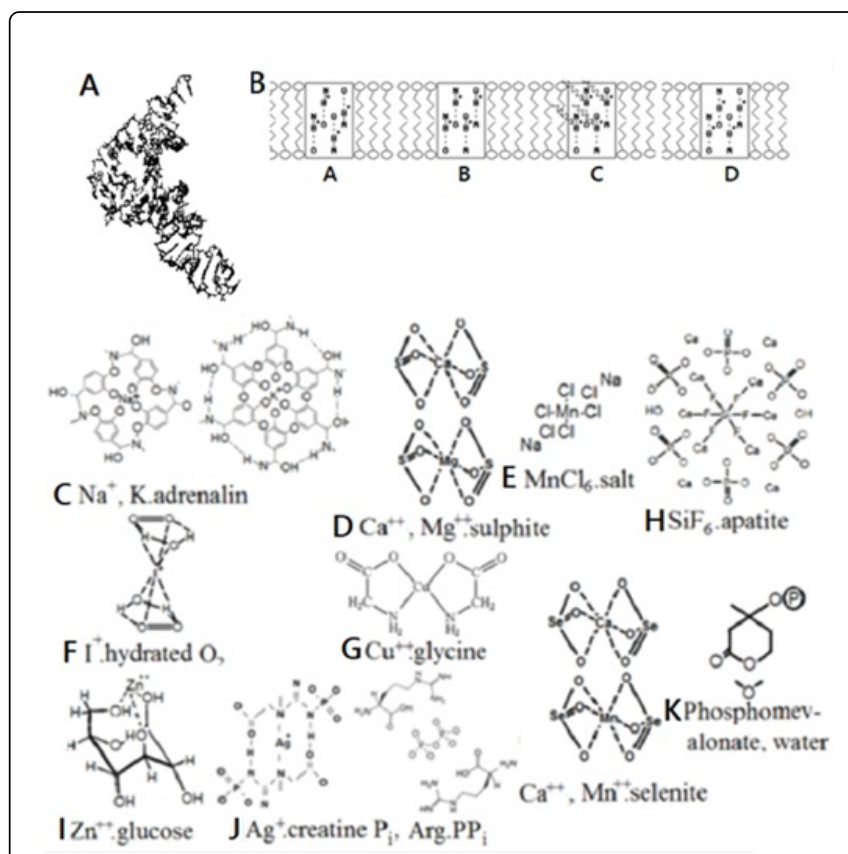

Figure 3: A. H-bond-lined hole through tRNAPhe [13], B. Ratchet mechanism, C. Active transport complexes. Trans-membrane $\mathrm{H}-$ bonds, $\mathrm{A}$ are aligned at $\mathrm{B}$, depolarized by infrared light, $\mathrm{C}$ and an electric field drives transport, D. C atecholamines exchange $3 \mathrm{Na}$ for $2 \mathrm{~K}$, D Sulphite exchanges $\mathrm{Ca}$ for $\mathrm{Mg}$, E. Manganese chlorides transport $\mathrm{NaCl}$, F. Iodinium transports oxygen, G. Copper carries amino acids, H. Silicon hexafluoride transports apatite, I. Zinc is carrier for glucose, J. Silver exchanges creatine for creatinine and orchestrates arginine.pyrophosphate transport, K. Selenite exchanges $\mathrm{Ca}$ for $\mathrm{Mn}$ and exchanging phospho-mevalonate for phosspho-mevalono-lactone transports water, contradicting Mitchell's chemiosmosis [14].

\section{Minions}

Minions comprise 1701 uncoiled DNA base pairs retaining B-helical base-pair spacing and overlap. Anti-parallel $\beta$-pleated protein hairpins with alternate neutral (Ala, Leu, Ile and Val) and basic (Arg and Lys) and Pro forming a U-bend hold them flat, Gramicidin $S$ has an analogous structure [4]. 21 hairpin units form a coil, (Figure 4A) and 9 coils bound by further hairpins complete a minion. Minions evolved to pack chromosomes, $\mathrm{C}$, ensuring their accurate copying, $\mathrm{B}$.

Reversed H-bonds on coil surfaces store 18-letter words using a 64-character alphabet. Minions holding similar words resonate, enabling memory recall. Axons and dendrites serve as optic cables, communicating with other nuclei (Table 1). 


\begin{tabular}{|c|c|c|c|c|c|}
\hline$\#$ & QUALITY & PERIOD & COLOUR & MASS & DISCIPLINE \\
\hline 9 & unity & $8.7 \mathrm{fs}$ & red & $\mathrm{me} / 7$ & $\begin{array}{l}\text { quantum } \\
\text { mechanics }\end{array}$ \\
\hline 8 & justice & $5.5 \mathrm{ps}$ & silver & $\mathrm{mp} / 7$ & physics \\
\hline$\overline{7}$ & stability & $350 \mathrm{ps}$ & blue & $2^{*} \mathrm{bp}$ mass & chemistry \\
\hline$\overline{5}$ & love & $1.4 \mu \mathrm{s}$ & bronze & $0.033 \mathrm{pg}$ & biochemistry \\
\hline- & peace & $87 \mu \mathrm{s}$ & yellow & $130 \mathrm{pg}$ & genetics \\
\hline$\overline{3}$ & beauty & $5.5 \mathrm{~ms}$ & pied & $0.51 \mu \mathrm{g}$ & biology \\
\hline$\overline{2}$ & truth & $350 \mathrm{~ms}$ & gold & $2 \mathrm{mg}$ & engineering \\
\hline$\overline{1}$ & goodness & $22 \mathrm{~s}$ & green & $8.1 \mathrm{~g}$ & psychology \\
\hline 1 & goodness & $23 \mathrm{~min}$ & green & $32 \mathrm{~kg}$ & psychiatry \\
\hline 2 & truth & 1 day $^{*}$ & gold & $130 t$ & head hunting \\
\hline 3 & beauty & 9 weeks & pied & $0.5 \mathrm{Mt}$ & sociology \\
\hline 4 & peace & $11 y^{*}$ & yellow & $2,000 \mathrm{Mt}$ & politics \\
\hline 5 & love & $685 y$ & bronze & $8 \mathrm{Gt}$ & history \\
\hline 6 & progress & $43 \mathrm{ky}$ & violet & $31 \mathrm{Pt}$ & archaeology \\
\hline 7 & stability & $2.7 \mathrm{My}$ & blue & 1.8* Moons & palaeontology \\
\hline 8 & justice & $170 \mathrm{My}$ & silver & $84^{\star}$ Earths & astronomy \\
\hline 9 & unity & $11 \mathrm{By}^{*}$ & red & $1^{*}$ Sun & cosmology \\
\hline
\end{tabular}

Table 1: Mental associations with minion coils. The numbers label inner and outer coil surfaces, ${ }^{*}$ connotes approximation. periods $=63 \mathrm{~N}$ $\tau$, colours feature in metaphors, adverts, flags and politics. Masses are in ratio 632, me \& $m p$ are electron \& proton masses, a, $\mathrm{f}, \mathrm{p}, \mathrm{n}, \mu, \mathrm{M}, \mathrm{P}$, $\mathrm{G} \& \mathrm{P}=10-18,10-15,10-12,10-9,10-6,106,109,1012 \& 1015$ respectively. Using $\mu=\sqrt{ } \mathrm{M}$ to measure mass makes Einstein's $E=M c 2$ symmetrical: $E=\mu 2 c 2$.

\section{Biological Cold Fusion}

Oscillating H-bonds accelerate protons along minion tunnels, Figure $4 \mathrm{~F}$. Representing fermions as planes according to the Tyger equation substitutes concentric polyhedra, G for electron orbitals, affording a new perspective on nuclear structure. Protons fuse with nuclei blocking their paths, driving the carbon nitrogen cycle, $H$ [15] and the $\gamma$-rays released follow Tyger curves, returning like boomerangs as pulsars [16] with matching periods and frequencies.
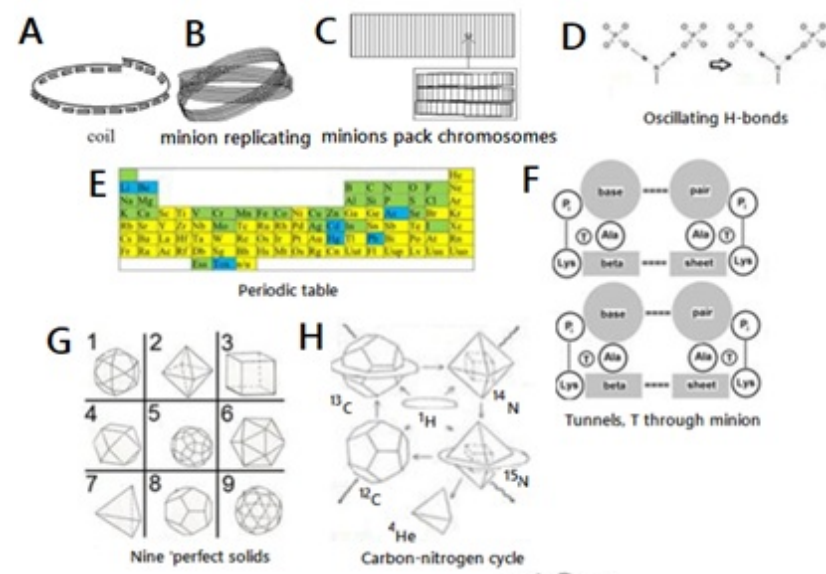

$\mathrm{H}$
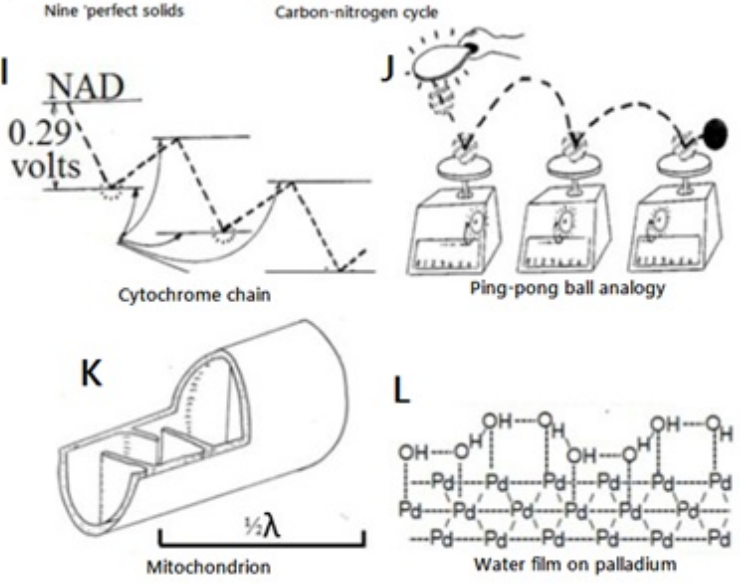

Figure 4: A. Minion coil, B. Replication, C. Chromosome packing, D. Oscillating H-bonds, E. Periodic table, F. Minion tunnels [T], G. Nine perfect solids, H. Carbon-nitrogen fusion cycle, I. Cytochrome chain, J. Ping-pong analogy, K. Mitochondrion, L. Cold fusion on palladium. Periodic table shows essential, toxic and unused elements in green, yellow and blue. Oscillating H-bonds flank tunnels, T, nine plane combinations forming 'perfect solids' simplify the carbon-nitrogen cycle.

\section{Conclusion}

A ping-pong ball bouncing on spring balances, Figure $4 \mathrm{~J}$ illustrates the cytochrome chain, I mitochondria are $1 / 2$-wave resonant cavities trapping $\lambda \sim 4 \mu$ energy, $K$. Something better than zeolites need be devised to harness $\gamma$-rays released by nuclear fusion in minions to address climate change. Cold fusion had a bad press following Fleischmann and Pons' observations of palladium crystals, Figure $4 \mathrm{~L}$ [17]. Water adsorbed on their surfaces creates tunnels analogous to those through minions. Readers persuaded to question quantum mechanics might devise ways to implement cold fusion. My book Science Uncoiled [5] details other consequences of my research, resolving malnutrition, ignorance and environmental problems.

\section{References}

1. Yen F, Chi Z (2015) Proton ordering dynamics of $\mathrm{H}_{2} \mathrm{O}$ ice. Phys Chem Chem Phys 17: 12458-12461. 
Citation: Deans MT (2016) Insights Arising When Quantum Mechanics is Reappraised From a Biological Perspective. Bioenergetics 5: 225. doi: $10.4172 / 2167-7662.1000225$

Page 5 of 5

2. Rattner JB, Hamkalo BA (1978) Higher order structure in metaphase chromosome; II. The relationship between the $250 \AA$ fiber, superbeads and beads-on-a- string. Chromosoma 69: 363-379.

3. L Pauling (1939) The nature of the chemical bond and the structure of molecules and crystals.

4. Lee DL, Hodges RS (2003) Structure-activity relationships of de novo designed cyclic antimicrobial peptides based on gramicidin $\mathrm{S}$. Biopolymers 71: 28-48.

5. Deans MT (2016) Science Uncoiled. Melrose.

6. Luger K, Mäder AW, Richmond RK, Sargent DF, Richmond TJ (1997) Crystal structure of the nucleosome core particle at 2.8 A resolution. Nature 389: 251-260.

7. Michelson AA, Albert A, Morley EW (1887) On the relative motion of the earth and the luminiferous ether. American Journal of Science 34: 333-345.

8. Einstein A (1927) Natural Sciences 15: 273-276.

9. Pauling L (1935) The structure and entropy of ice and of other crystals with some randomness of atomic arrangement. J Am Chem Soc 57: 2680-2684.
10. Darwin C (1859) On the origin of species.

11. Traut T (2014) De Novo Nucleotide Synthesis.

12. de Jong HGB (1932) Proposed coacervates, championed by Soviet biochemist A. I. Oparin in his book The Origin of Life.

13. Sussman JL, Kim S (1976) Three-dimensional structure of a transfer rna in two crystal forms. Science 192: 853-858.

14. Mitchell P (1961) Coupling of phosphorylation to electron and hydrogen transfer by a chemi-osmotic type of mechanism. Nature 191: 144-148.

15. Weizsäcker CV , Bethe H (1938) Independently proposed the carbonnitrogen cycle. J Electroanal Chem 261: 301-308.

16. Hewish A, Bell SJ, Pilkington JDH, Scott PF, Collins RA (1968) Observation of a rapidly pulsating radio source . Nature 217: 709-713.

17. Fleischmann M, Pons S (1989) Electrochemically induced nuclear fusion of deuterium. Journal of Electroanalytical Chemistry 261: 301-308. 